\title{
Effects of the Grinding Wheel Eccentricity and Waviness on the Dynamics of Tool Grinding
}

\author{
Kristin Miriam de Payrebrune ${ }^{1, a *}$, Matthias Kröger ${ }^{2, b}$ \\ ${ }^{1}$ Technische Universität Kaiserslautern, Department of Applied Structural Mechanics, \\ Erwin-Schrödinger Straße 56, 67663 Kaiserslautern, Germany \\ ${ }^{2}$ TU Bergakademie Freiberg, Institute for Machine Elements, Design and Manufacturing, \\ Agricolastraße 1, 09599 Freiberg, Germany \\ akristin.payrebrune@mv.uni-kl.de, ${ }^{\mathrm{b}}$ Kroeger@imkf.tu-freiberg.de
}

Keywords: Tool grinding, Grinding wheel, Wear and topography model, System dynamics.

\begin{abstract}
The complex dynamics of grinding repeatedly cause critical or unstable process conditions. For a better understanding and prediction of such occurrences, the dominant excitation phenomena need to be identified and their interrelation with the system dynamics have to be analyzed.

Based on measurements of the excited frequencies in several operation modes of the grinding machine, the grinding wheel rotation is identified as a major excitation source. Further analysis of the grinding wheel surface displays three main components that define the excitation frequencies of the system; these are the eccentricity, waviness and roughness (also named wheel topography). Moreover, the wheel topography and thus the excitation frequencies can change over time due to excessive wear.

Following the experimental results, a grinding wheel topography and wear model are developed and included in an integrated simulation of tool grinding. The analysis of the calculated cutting forces in the frequency domain confirm the excitation due to the grinding wheel topography.

Firstly, this work has extracted the grinding wheel as a prominent excitation mechanism and reproduced it with the developed grinding model. Secondly, we have evidence that a complete description of the complex grinding process is only possible when considering the interdependence between system dynamics, wheel kinematics and the grinding process.
\end{abstract}

\section{Introduction}

Being a high-precision manufacturing process, grinding is an operation placed at the end of the manufacturing chain. The development of high-power grinding processes enable this manufacturing method to be a geometry defining operation with high material removal rates, as in creep-feed grinding and tool grinding. Nevertheless, inaccuracies, chatter or overheat directly affect the quality of machined parts and lead to high failure costs.

Grinding models aimed at optimizing the manufacturing process, predicting the quality of the machined part, and estimating unstable operation settings, are of particular interest to the industry. This requires knowledge on the interactions among machinery, workpiece and process during grinding, which was already the subject of many research activities [1-3].

The developed grinding models can thereby be grouped in models focusing on the dynamics of the machine or the workpiece $[1,2,4,5]$, and in kinematic models focusing on the penetration and material removal during the grinding process $[6,7]$. The kinematic models describe the path of single grains, mostly in $2 \mathrm{D}$, their depth of cut and the topography of the grinding wheel. The grinding wheel topography is represented by surface scans, or is artificially generated by randomly combined geometric bodies, as spheres, cuboids, tetrahedrons or octahedrons [8-10]. In these models, the dynamics of workpiece and machinery are mostly neglected or only considered in a simplified manner. In contrast, the models describing the dynamics of machinery or workpiece mostly reduce the geometry of the penetrating parts to ideal round discs. 
However, in order to describe the complex interactions during grinding, the dynamics and kinematics cannot be treated independently [11-13]. Moreover, measurements have shown that the penetration of the grinding wheel excites the workpiece and causes the whole system to vibrate. Specifically in tool grinding, for which the machined drill or chamfer are clamped as a cantilevering beam only on one side, the excitation due to the grinding wheel eccentricity, waviness, and roughness is dominant.

In this work, we first illustrate the dominant effect of the grinding wheel penetration on the excitation. Later, we introduce a model of the grinding wheel topography. Finally, to cover timedependent changes of the excitation frequency, we introduce a wear model for the grinding wheel topography. In combination with models of the workpiece dynamics, the cutting forces and the material removal, the tool grinding process is fully modeled. This tool grinding model is briefly described in the section Results and Discussion and simulation results that highlight the influence of the wheel topography on the excitation of the whole system are shown.

\section{Dynamics in tool grinding}

During grinding, numerous frequencies are excited simultaneously. In tool grinding especially, the frequencies of the workpiece oscillations are of particular interest because they can lead to unwanted size inaccuracies or chatter. Hence, in order to assign detected frequencies to specific components of the used five axis CNC grinding machine (cf. Fig. 1) from Walter Maschinenbau $\mathrm{GmbH} \mathrm{[14]} \mathrm{or} \mathrm{to} \mathrm{the} \mathrm{process} \mathrm{itself,} \mathrm{we} \mathrm{investigated} \mathrm{five} \mathrm{different} \mathrm{operating} \mathrm{modes,} \mathrm{which} \mathrm{are:}$

mode 1: basic state, machine control, centrifuge, and axis motors are turned on,

mode 2: $\quad$ mode 1 plus rotation of grinding wheel $(18 \mathrm{~m} / \mathrm{s} \sim 45 \mathrm{~Hz})$,

mode 3: mode 2 plus flow of coolant (pressure $\sim 6$ bar),

mode 4: mode 3 plus air-grinding (without material removal),

mode 5: mode 3 plus grinding a helical flute.

For each operating mode, the forces acting on the workpiece are recorded with $20 \mathrm{kHz}$ with a three component force-measurement platform from Kistler. The sensor platform was installed below the machine table. To analyze the recorded forces, they are transformed into the frequency domain by a Fast Fourier Transformation (FFT).

a)

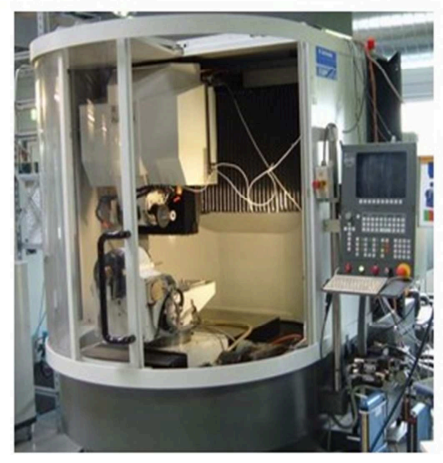

b)

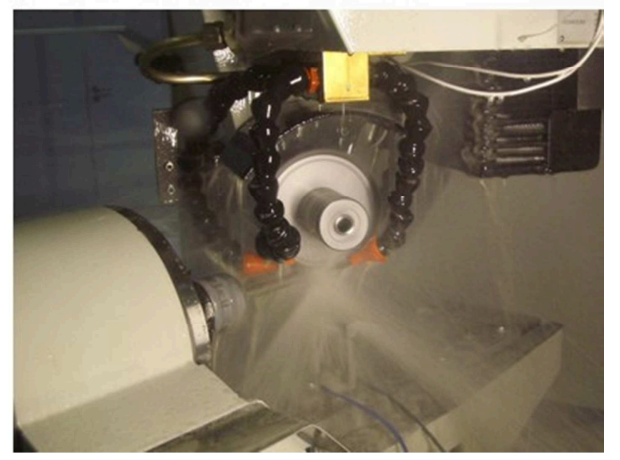

Figure 1: Five axis CNC grinding machine used for grinding experiments a) and detailed view of grinding wheel and workpiece during machining ${ }^{1}$

Fig. 2. shows the evolution of the frequencies and makes a direct correlation to specific operating modes. To allow a better comparison between the operating modes, the frequencies were divided by their absolute maximum value at mode 5.

During the basic state, a frequency of $1000 \mathrm{~Hz}$ appears and continues in all following operating modes. This frequency is related to the rotation of the centrifuge, which cleans the coolant before reuse. The second visible frequency at $50 \mathrm{~Hz}$ is the supply frequency, which is also measured when the machine is totally shut down and the measuring equipment operates alone.

\footnotetext{
1 The grinding experiments have gratefully been carried out at the project partner, the Institute of Production Engineering and Machine Tools at the Leibniz Universität Hannover during the DFG priority program SPP 1180
} 
In the second operating mode, when the grinding wheel is turned on, a frequency at $275 \mathrm{~Hz}$ is visible which does not correspond to the grinding wheel rotational frequency of $45 \mathrm{~Hz}$. Finite element simulations of the machine show that the measured frequency belongs to the first Eigen mode of the spindle, which gets excited, see Fig. 3.

In the operating mode 3 , the additional flow of coolant drastically damps the natural vibration of the spindle. However, because the new occurring frequency at $63 \mathrm{~Hz}$ is not visible in the following operating modes, it cannot be directly related to the coolant.
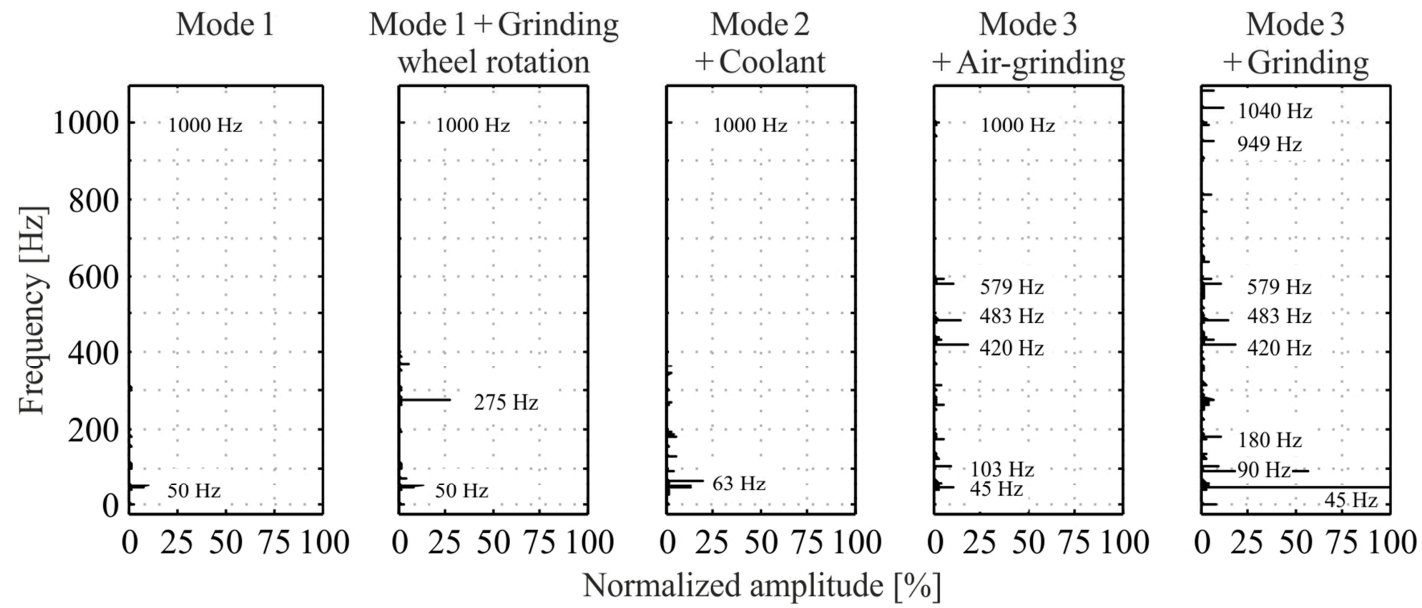

Figure 2: Frequency plots of the investigated operating modes of the five axis CNC grinding machine in Fig. 1

During air-grinding with $10 \mathrm{~mm}$ offset between the grinding wheel and workpiece, frequencies of $420 \mathrm{~Hz}, 483 \mathrm{~Hz}$ and $579 \mathrm{~Hz}$ corresponding to axis movements, appear. Additional analyses of these frequencies highlight that they only occur during combined axis movements. Furthermore, these axis movements cause an excitation of the eigenfrequency of the machine structure at $103 \mathrm{~Hz}$, which is proved with the carried finite element analyses. We would also like to highlight that the frequency of the rotating grinding wheel $(45 \mathrm{~Hz})$ is visible for the first time.

This frequency becomes most dominant when grinding a helical flute without offset and can be related to an eccentricity. Also, frequencies of $90 \mathrm{~Hz}$ and $180 \mathrm{~Hz}$ and some higher harmonics around $1000 \mathrm{~Hz}$ become obvious in this operating mode. Such frequencies are either related to the second and fourth harmonic of the eccentricity or to surface waves in the grinding wheel.
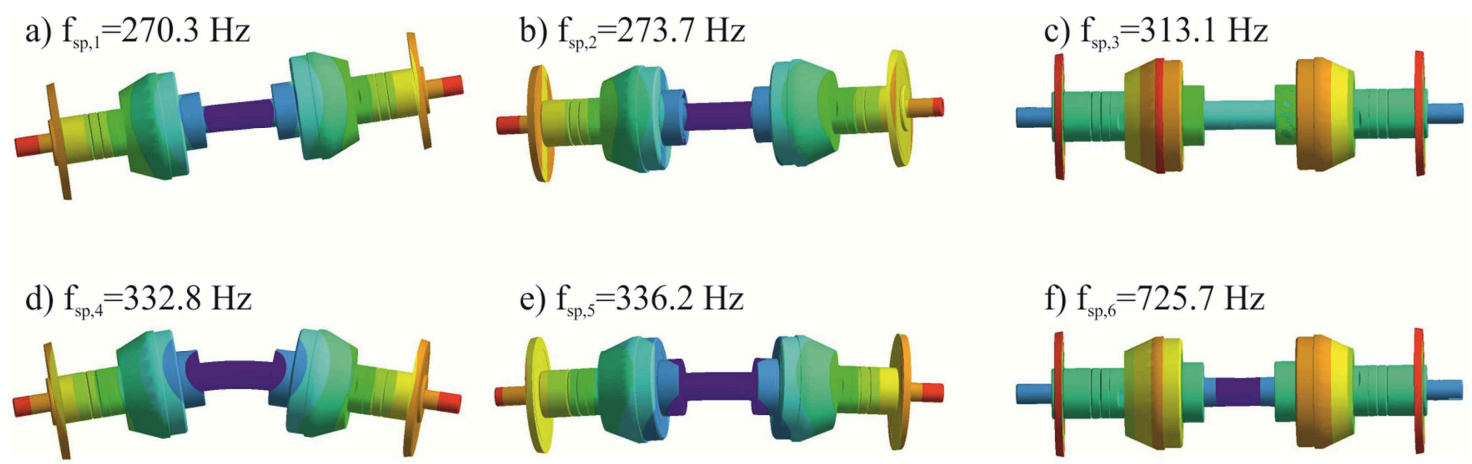

Figure 3: Finite element analysis of the first Eigen modes of the double-spindle; the first bending mode in a) and b) and the second bending mode in d) and e) display two spatial movements of the same eigenfrequency in each case. Additionally, the first c) and second f) longitudinal modes are illustrated

In repeated grinding experiments with various wheel speeds, the dominant frequency shifts accordingly (cf. Fig. 11). Hence, the results lead to the conclusion that the rotating grinding wheel along with its macroscopic topography (eccentricity, waviness) is the strongest excitation source. Regarding the externally caused workpiece vibrations, these oscillations are a direct response to the micro- and macroscopic topography of the grinding wheel. To accurately display this excitation mechanism, the grinding wheel topography has to be modeled precisely. Hence, the following section shows results of additional investigations of the grinding wheel topography and its numerical description. 


\section{Grinding wheel model}

The grinding wheel is composed of abrasive grains embedded in a binding material. Throughout the grinding process, the abrasive grains are subjected to wear and can flatten, break, or fall out. This causes a permanent change in the microscopic grinding wheel topography, which also influences its macroscopic geometry by extensive wear.

To reproduce the changing excitation source in the grinding simulation, the grinding wheel model has to represent the microscopic and macroscopic topography, which change due to wear. Based on experimental investigations, these aspects are studied and a grinding wheel model is developed.

Topography Model. In order to identify significant parameters to describe the topography, several grinding wheel surfaces were analyzed on a special test stand. The wheels were mounted on a slowly rotating motor with $400 \mathrm{rpm}$ and the surface was measured by a triangulation laser (opto NCDC2200 of micro epsilon) with a circumferential resolution of about $32 \mu \mathrm{m}$. The measured surface line was then analyzed.

In particular, we measured the surface of two high performance cylindrical diamond wheels SP1A1-125-15-1020*D64(D91) Q-Flute C from Winter Saint Gobain [15], and two fine and coarse low performance wheels with white corundum $(150 \times 20 \times 32 / 20 \quad 30 \mathrm{~A} 54 / 001$ M8 V568 and 150x20x32/20 30A 36/01 K6 V25) and silicon carbide (150x20x32/20 60C 60/11 Jot7 V584 and 150x20x32/20 60C 46/11 Jot7 V84) from Werkzeughandel Maschinenhandel Meyer [16]. The high performance wheels were previously used in grinding experiments of tungsten carbide and high speed steel (HSS), so that they show signs of wear. The low performance wheels were new and used for additional wear tests.

Based on all measured surface lines, three significant values are identified to sufficiently describe the microscopic and macroscopic topography of a grinding wheel. These components are eccentricity, waviness and roughness. Fig. 4 illustrates the originally measured surface line of the diamond wheel with a grain size of $64 \mu \mathrm{m}$ and the filtered microscopic and macroscopic components. The low-pass filters with $\mathrm{f}<15 \mathrm{~Hz}$ and band-pass filter with $15 \mathrm{~Hz}<\mathrm{f}<150 \mathrm{~Hz}$ highlight the macroscopic out-of-roundness of the wheel and the surface waves, respectively. Because the wheel was used for grinding and is already worn out, the amplitudes are overstated but more apparent.

With a high pass filter ( $\mathrm{f}>150 \mathrm{~Hz}$ ), the roughness of the microscopic topography becomes visible. Here, positive values are related to protruding grains, whereas negative vales indicate removed grains. The values of the measured roughness do not exceed the limits $\pm d_{\text {grain }}$ with the grain size $d_{\text {grain }}$. For a more detailed description of the measuring procedure and results, we refer the reader to our earlier work presented in [17].

a)

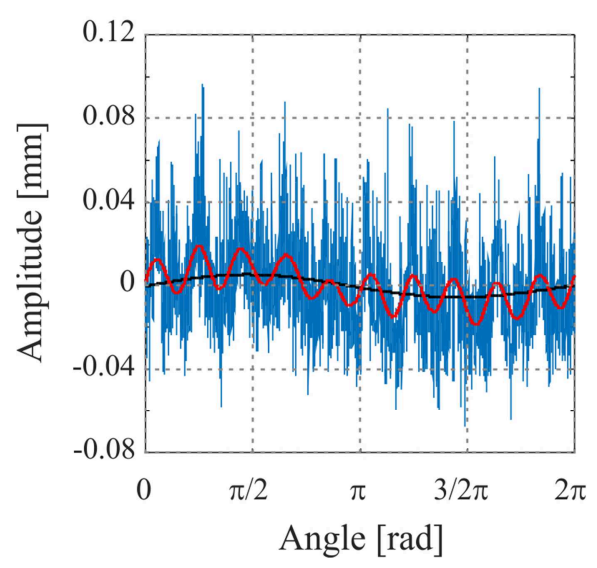

b)

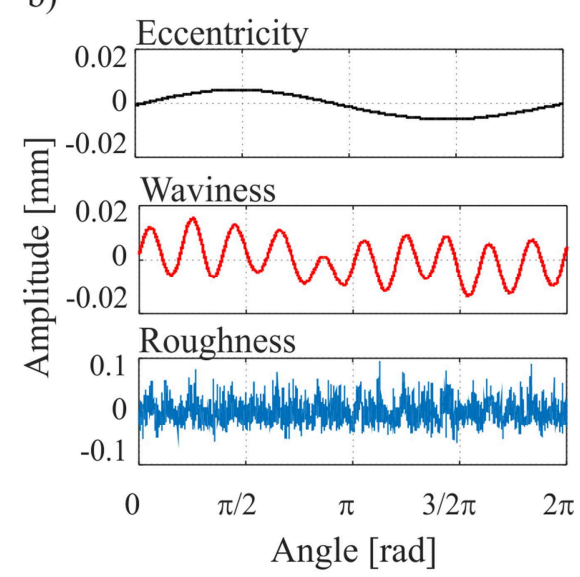

Figure 4: Measured topography of the grinding wheel SP1A1-125-15-1020*D64 with diamond grains of $64 \mu \mathrm{m}$ : a) unfiltered data and b) filtered macroscopic and microscopic components [17] 
The additionally investigated grinding wheels show similar results. In general, the macroscopic grinding wheel topography is composed of an eccentric and undulating part. The roughness represents the microscopic topography for which a normal frequency distribution was found [1719].

The grinding wheel can be numerically described by sine waves for the eccentricity and waviness, the corresponding amplitudes $\hat{e}$ and $\hat{c}$, a phase shift $\psi$ for the waviness, and a normally distributed noise for the roughness in the limits of the grain size. To consider the absolute dimensions, these components have to be added to the nominal radius $R_{0}$ of the grinding wheel

$$
R(\varphi)=R_{0}+\underbrace{\hat{e} \cdot \sin (\varphi)}_{\text {eccentricity }}+\underbrace{\hat{c} \cdot \sin (n \varphi+\psi)}_{\text {waviness }}+\underbrace{n_{\text {rough }} \cdot g(\varphi)}_{\text {roughness }}
$$

Using this description, general grinding wheel topographies can be easily generated and used for overall grinding simulations. Including the measured amplitudes of eccentricity and waviness in Eq. 1, one surface line was generated from the cylindrical grinding wheel SP1A1-125-15$1020^{*} \mathrm{D} 64$, and compared to the measured data, cf. Fig. 5. The very good match of the generated grinding wheel surface motivates the idea that the complex excitation of the workpiece is also feasible.

a)

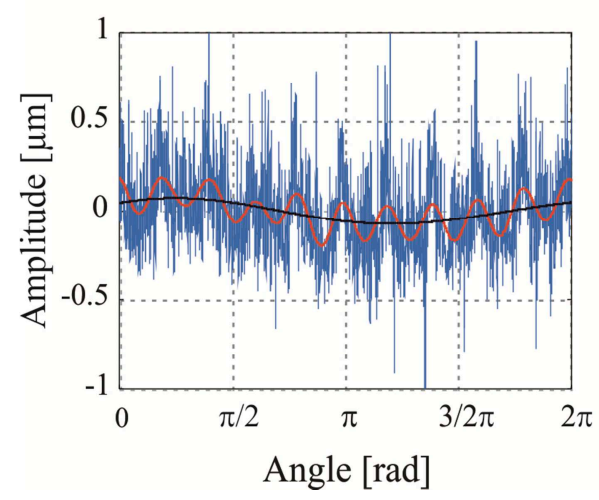

b)

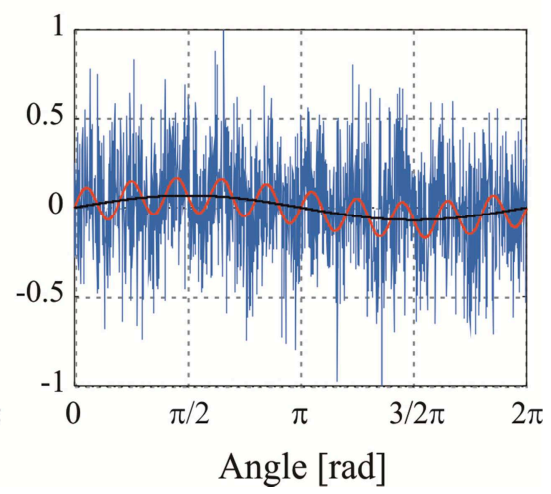

Figure 5: Macroscopic and microscopic grinding wheel topography with eccentricity, waviness and roughness a) measured and b) generated [17]

Wear Model. Wear is a continuous process that affects the macroscopic and microscopic grinding wheel topography. A change in diameter and the appearance of surface waves are types of macroscopic wear. Flattening, breakage or grains falling out of the bond are types of microscopic wear.

The change in the wheel surface due to macroscopic wear affects the excitation of the workpiece and the stability of the system. The microscopic flattening of grains increases the amount of ploughing and grooving during the material removing process, which causes an increase of cutting forces. In contrast, when the grains break or fall out, new, sharp cutting edges appear and ensure a constant cutting performance of the grinding wheel.

To investigate macroscopic and microscopic wear phenomena, grinding experiments are carried out with a white corundum grinding wheel $150 \times 20 \times 32 / 2030 \mathrm{~A} 36 / 01 \mathrm{~K} 6 \mathrm{~V} 25$. This wheel is significantly less wear-resistant than diamond wheels and thus makes the investigation more convenient. On a special test stand, shown in Fig. 6, the unused white corundum grinding wheel is mounted on a motor with an eccentricity of $280 \mu \mathrm{m}$.

For the workpiece, a semi-finished structural steel S235JR is used with a cross section of $10 \mathrm{~mm}$ $\mathrm{x} 10 \mathrm{~mm}$ and a length of $200 \mathrm{~mm}$. It is mounted on a force sensor on top of an adjustable table that moves on a linear guide system. For each grinding experiment, the infeed of the grinding wheel is set to $100 \mu \mathrm{m}$, the feed speed to $40 \mathrm{~mm} / \mathrm{s}$, and the cutting speed to $18 \mathrm{~m} / \mathrm{s}$. The experiments use counter direction grinding without coolant. 
Every 20 experiments, the surface of the grinding wheel is measured by the triangulation laser. One experiment last for $2 \mathrm{~s}$ and covers a grinding distance of $80 \mathrm{~mm}$. Additionally, forces are recorded throughout.

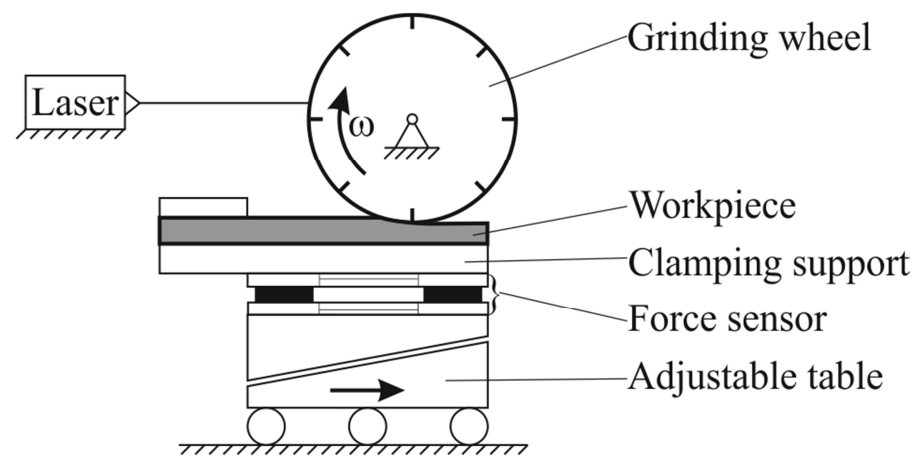

Figure 6: Schematic of the test setup to investigate wear of a white corundum grinding wheel

Fig. 7 displays the relative change of the wheel surface and the progression of cutting forces over 5 wheel revolutions. After $40 \mathrm{~s}$, due to the eccentricity the dominant peak is already reduced by half and the cutting forces are more homogeneous. After $80 \mathrm{~s}$, the macroscopic wheel topography has dramatically changed. Instead of one dominant sine wave due to the eccentricity, now two dominant waves appear as result of a superposed eccentricity and waviness.

a)

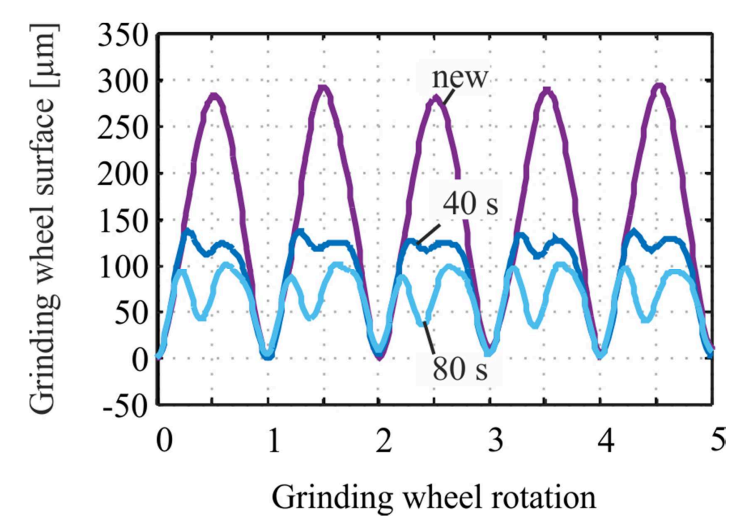

b)

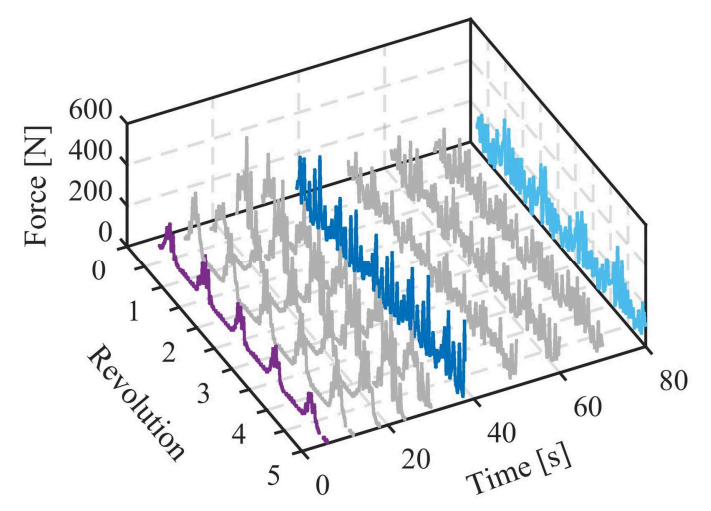

Figure 7: Evolution of wear on the white corundum grinding wheel (150x20x32/20 30A 36/01 K6 V25) during grinding structural steel. Five revolutions of the measured macroscopic geometry of the grinding wheel with an initial eccentricity of $280 \mu \mathrm{m}$ a). Evolution of the corresponding cutting forces vs. time and revolution b)

Including wear in the grinding wheel description is important to cover time-dependent excitation effects. A general and suitable way is to introduce a wear indicator. This parameter measures the local force acting at a discrete position on the grinding wheel over time, and increases to a certain threshold that corresponds to when the grain brakes from the bond. More in-depth studies, as e.g. the analysis of the number of cycles required to fatigue the bonding of a single grain, can identify this threshold value.

To verify the principle feasibility of the wear modeling procedure we include in the grinding wheel model a linear fatigue hypothesis of the wear indicator

$$
I_{\text {wear }}\left(t_{i}\right)=\left\{\begin{array}{ccc}
I_{\text {wear }}\left(t_{i-1}\right)+s_{\text {wear }} \cdot F_{N}\left(t_{i}\right) \Delta t \\
0
\end{array} \text { for } \begin{array}{c}
I_{\text {wear }}\left(t_{i}\right)<1 \\
I_{\text {wear }}\left(t_{i}\right) \geq 1
\end{array}\right.
$$

In Eq. 2, $s_{\text {wear }}$ is a wear factor that describes the increase of the wear indicator $I_{\text {wear }}$ until it reaches the threshold value of 1 . At this value the corresponding point on the grinding wheel is reduced by the diameter of one grain, imitating the loss of a grain. Fig. 8 illustrates that the microscopic modification of the topography leads to a macroscopic change of the grinding wheel surface. A continuous longitudinal grinding is simulated with process parameters: feed speed of 
$100 \mathrm{~mm} / \mathrm{min}$, cutting speed of $18 \mathrm{~m} / \mathrm{s}$, and infeed of $2 \mathrm{~mm}$. This simulation shows that a flute is produced in an ideal stiff workpiece. To enforce significant macroscopic wear during the simulated time of $12 \mathrm{~s}$, the grinding wheel is modeled as ideal disc with an eccentricity of $250 \mu \mathrm{m}$ and an overestimated wear factor $s_{\text {wear }} \cdot \Delta t=1$.

Fig. 8a) displays the change of the grinding wheel surface over time. Fig. 8b) shows the calculated corresponding cutting forces. During the run-in time, when the grinding wheel slowly contacts the workpiece, the cutting forces increase up to a maximum of $200 \mathrm{~N}$ at $2 \mathrm{~s}$. During this time, no significant wear of the grinding wheel is detected but the wear indicator does increase. Eventually, after some time with high cutting forces, wear starts and changes the macroscopic wheel geometry. Simultaneously, the cutting forces decrease because the local infeed of the grinding wheel is reduced. At $7 \mathrm{~s}$ the change of the wheel geometry leads to two distinct peaks and consequently to two discrete peaks of increased cutting force.

Also in the frequency plot (Fig. 8c)), a drastic change is noticeable at $7 \mathrm{~s}$. The interaction of the wheel rotation and the eigenfrequencies of the system cause a harmonic excitation of frequencies up to $1000 \mathrm{~Hz}$.

a)

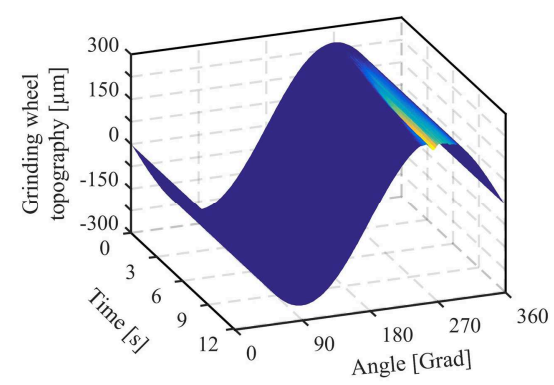

b)

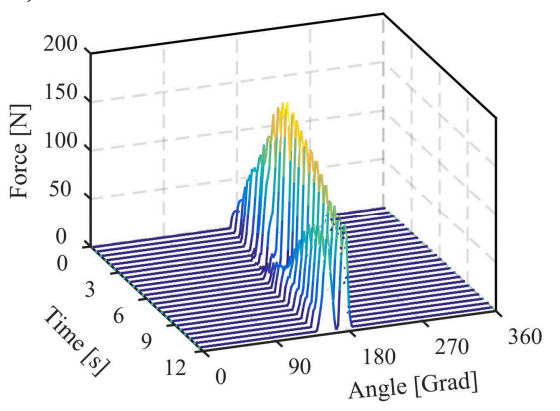

c)

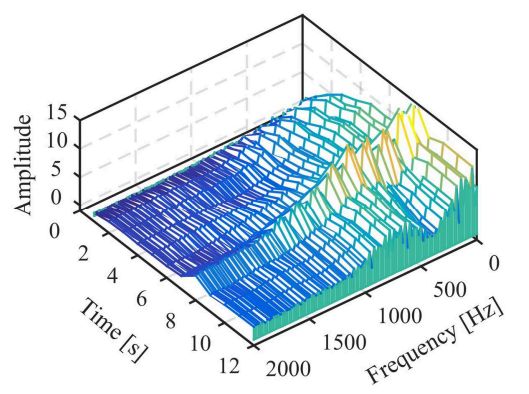

Figure 8: Results of grinding simulation with wear. Evolution of the macroscopic grinding wheel surface vs. time and angular position a). Simulated cutting forces of the grinding process vs. time and angular position b) and the corresponding excitation frequencies c)

\section{Results and Discussion}

The investigations of grinding wheel surface and wear underline the significance of the macroscopic topography (eccentricity and waviness) on the dynamic excitation of the workpiece and machine structure in grinding. The results feed into a model of the overall grinding process, developed by the authors [20,21]. This model includes a description of the dynamics of the workpiece [22], contact and material removal [17], empirical cutting forces, and grinding wheel topography and wear. Additionally, a temperature model exists that estimates the workpiece temperature through the calculated cutting forces, see Fig. 9. 
a)

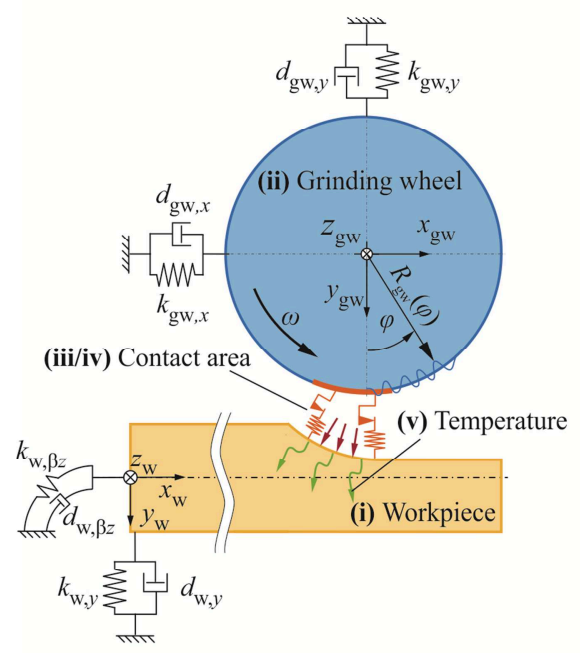

b)

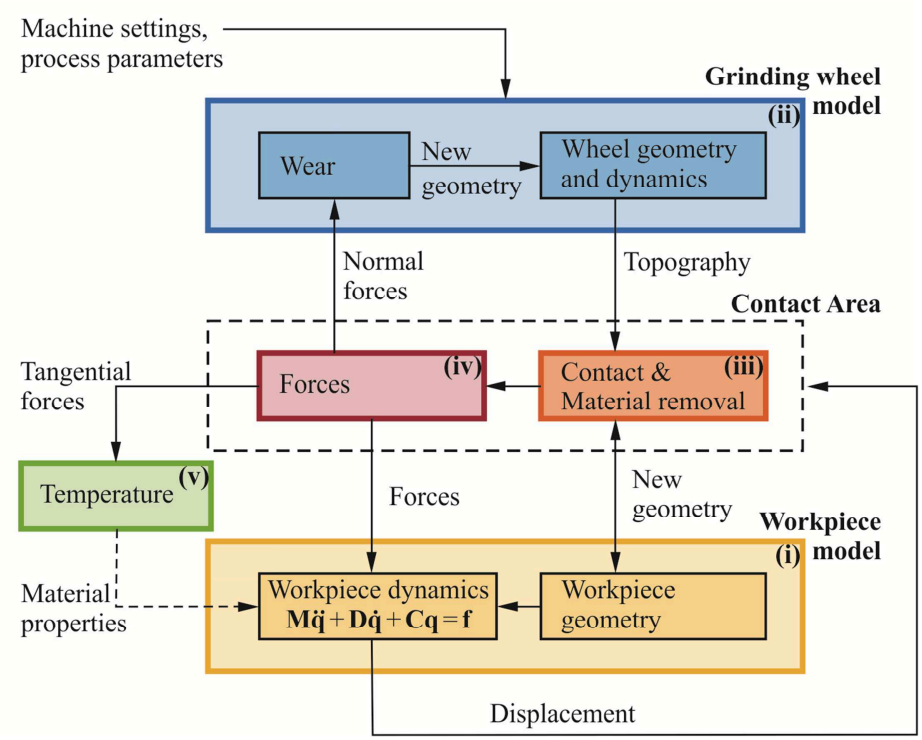

Figure 9: Schematic of the overall grinding model a). Block diagram showing the interrelation of different aspects of the model b) [21]

The coupling of all modeled parts enables the characterization of complex phenomena. These phenomena only arise due to strong interactions between the components. In particular, the excitation caused by the grinding wheel topography causes a periodic deflection of the workpiece. This leads to variable contact situations and variable cutting forces. Consequently, the analysis of the simulated cutting forces in the frequency domain should reflect the eccentricity and waviness of the grinding wheel.

To validate this assumption, grinding simulations were carried out for three different grinding wheel rotations with frequencies of $f=30.6 \mathrm{~Hz}, 45.8 \mathrm{~Hz}$ and $61.1 \mathrm{~Hz}$, and compared to corresponding experiments. With a diameter of $d=125 \mathrm{~mm}$, the corresponding cutting speeds of $v_{c}=12 \mathrm{~m} / \mathrm{s}, 18 \mathrm{~m} / \mathrm{s}$ and $24 \mathrm{~m} / \mathrm{s}$ were used. Based on detailed grinding wheel studies, as described in [17], we have used a superposed eccentricity and waviness of 4 sine waves. Further, the workpiece was modeled as an elastic Euler-Bernoulli beam with a cantilevering length of $100 \mathrm{~mm}$ and a diameter of $10 \mathrm{~mm}$. In both experiment and simulation, a longitudinal flute of $50 \mathrm{~mm}$ was generated after $30 \mathrm{~s}$. The cutting forces were calculated with a time increment of $10^{-4} \mathrm{~s}$. Fig. 10 displays the final result of the measured and calculated cutting forces in the vertical direction.

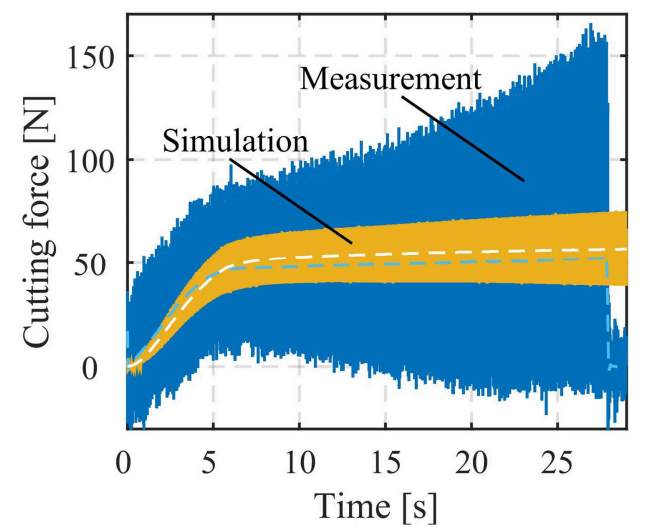

Figure 10: Measured and simulated cutting forces while grinding a longitudinal flute in tungsten carbide. Process parameters are: cutting speed $18 \mathrm{~m} / \mathrm{s}$, infeed $2 \mathrm{~mm}$ and feed speed $100 \mathrm{~mm} / \mathrm{min}$

At the beginning of the process, when the grinding wheel first contacts the workpiece, the cutting forces increase till the grinding wheel has regular contact. At steady state (after about $6 \mathrm{~s}$ ), the mean values (dashed lines) only slightly increase, whereas the measured force strongly oscillates. The slight increase in the mean values result from the deflection of the workpiece, which becomes stiffer 
as the grinding wheel moves towards clamping. Consequently, the local penetration of the abrasive grains increase and cause the disproportionate increase in amplitude.

The overall tool grinding model represents the increase of the mean value well, but underestimates the amplitudes of cutting forces. This discrepancy may be related to coolant effects which were neglected, but impinge the workpiece at 6 bar. Another reason could be insufficiencies in the empirical force model. Nevertheless, the interrelation between the workpiece structure, grinding wheel, and process is represented correctly and the model can be used to study the grinding process in more detail.

Regarding the excitation frequencies of the system, we have transformed the simulated and measured cutting forces by a Fast Fourier analysis. The plots in Fig. 11 illustrate the excitation frequencies during the experiment (blue) and the simulation (yellow). Marked by numbers, the first and fourth harmonics are clearly visible in both the simulation and experiment. The values correlate with the predefined frequencies. The measured data additionally display the second and third harmonic, as already noted in Fig. 2. Surface waves on the grinding wheel with various wave numbers might be the reason for the additional harmonics.

Overall, the results clearly illustrate the excitation mechanism caused by the grinding wheel topography. The results are correctly reproduced in the simulation. Thus the necessary condition to study the dynamics of grinding is satisfied.

a)

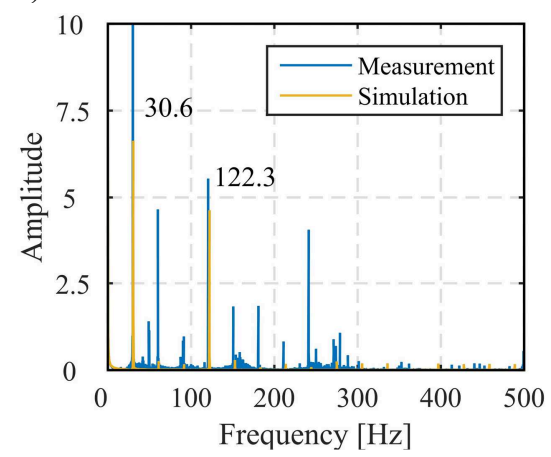

b)

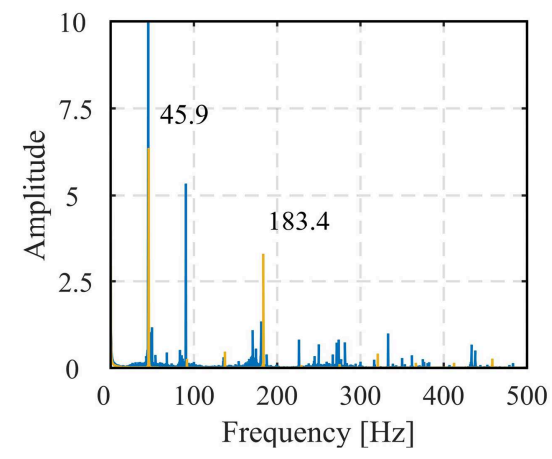

c)

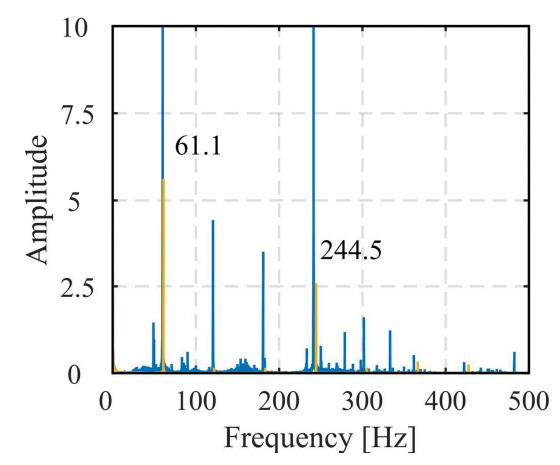

Figure 11: Frequency plots of the measured and simulated cutting forces with frequencies of $30.6 \mathrm{~Hz}$ a), $45.9 \mathrm{~Hz}$ b) and $61.1 \mathrm{~Hz}$ c). Generated by a grinding wheel with an eccentricity and 4 surface waves

\section{Summary}

Grinding, machining with geometrically undefined cutting edges, is a highly complex process. To understand and predict critical process situations, we need to know the excitation mechanism and the interdependence between the grinding wheel, structure and material removal process.

In this work, the excitation sources are investigated under several operating modes. The grinding wheel rotation and its macroscopic geometry are identified as the dominant excitation sources. These observations are followed by a detailed analysis of the macroscopic and microscopic grinding wheel topography. The investigation of several grinding wheels show macroscopic eccentricity and waviness, and microscopic roughness. Studies of the grinding wheel wear illustrate that wear may impact the macroscopic topography, as e.g. the numbers of surface waves. A change in topography will result in changing excitation frequencies during machining, which can cause instable process conditions. Hence, for long grinding observations, wear has to be considered.

In summary, a grinding wheel model is developed that represents the macroscopic and microscopic components, and includes a wear indicator to adjust the topography. This model is included in an overall tool grinding model and predicts the cutting forces with high time resolution. The analyzed cutting forces reflect the influence of the macroscopic wheel topography and match the measured observations.

This work confirms the dominant influence of grinding wheel topography on excitation and encourages the coupled treatment of structural dynamics and wheel kinematics in grinding. 


\section{Acknowledgment}

We take this opportunity to thank the Institute of Production Engineering and Machine Tools (IFW) of the Leibniz Universität Hannover, where the grinding experiments were conducted. We further appreciate the funding of the project (KR2122-2/3) by the German Research Foundation (DFG), which was integrated in the Priority Program SPP 1180 "Prediction and Manipulation of Interactions between Structure and Process". We also thank Abdulrahman Jbaily and Spencer Frank for their helpful comments on an earlier draft and the anonymous reviewers for their thoughtful and constructive criticisms that helped improve the paper.

\section{References}

[1] C. Brecher, M. Esser, S. Witt, Interaction of manufacturing process and machine tool, CIRP Annals - Manufacturing Technology. 58 (2009) 588-607.

[2] E. Brinksmeier, J.C. Aurich, E. Govekar, C. Heinzel, H.-W. Hoffmeister, F. Klocke, J. Peters, R. Rentsch, D.J. Stephenson, E. Uhlmann, K. Weinert, M. Wittmann. Advances in Modeling and Simulation of Grinding Processes. CIRP Annals - Manufacturing Technology. 55 (2006) 667-696.

[3] B. Denkena, F. Hollmann, Process Machine Interactions, Springer, Berlin Heidelberg, 2013.

[4] H.K. Tönshoff, B. Denkena, J. Jacobsen, B. Heimann, O. Schütte, K. Grudzinski, A. Bodnar, Nonlinear Dynamics of an External Cylindrical Grinding System and a Strategy for Chatter Compensation. Nonlinear Dynamics Production Systems (2004) 187-207.

[5] M. Weck, N. Hennes, A. Schulz, Dynamic Behaviour of Cylindrical Traverse Grinding Processes, CIRP Annals - Manufacturing Technology. 50 (2001) 213-216.

[6] W.L. Cooper, A.S. Lavine, Grinding Process Size Effect and Kinematics Numerical Analysis, J. Manufacturing Science Engineering. 122 (2000) 59-69.

[7] T.A. Nguyen, D.L. Butler, Simulation of precision grinding process, Part 1: generation of the grinding wheel surface. Int. J. Machine Tools Manufacture. 45 (2005) 1321-1328.

[8] X. Chen, W.B. Rowe, Analysis and simulation of the grinding process. Part I: Generation of the grinding wheel surface. Int. J. Machine Tools Manufacture. 36 (1996) 871-882.

[9] I. Inasaki, Grinding Process Simulation Based on the Wheel Topography Measurement, CIRP Annals - Manufacturing Technology. 45 (1996) 347-350.

[10] G. Warnecke, U. Zitt, Kinematic Simulation for Analyzing and Predicting High-Performance Grinding Processes, CIRP Annals - Manufacturing Technology. 47 (1998) 265-270.

[11] Y. Altintas, M.Weck, Chatter Stability of Metal Cutting and Grinding, CIRP Annals Manufacturing Technology. 53, 2 (2004) 619-642.

[12] J. Badger, S. Murphy, G. O'Donnell, The effect of wheel eccentricity and run-out on grinding forces, waviness, wheel wear and chatter, International Journal of Machine Tools and Manufacture. 51 (2011) 766-774.

[13] I. Inasaki, B. Karpuschewski, H.-S. Lee, Grinding Chatter - Origin and Suppression, CIRP Annals - Manufacturing Technology. 50, 2 (2001) 515-534.

[14] Information on http://www.walter-machines.com

[15] Information on http://www.winter-superabrasives.com

[16] Information on https://www.holz-metall.info/shop1/artike19304.htm 
[17] K.M. de Payrebrune, M. Kröger, Reduced models of grinding wheel topography and material removal to simulate dynamical aspects in grinding, Int. J. of Advanced Manufacturing Technology. 88 (2016) 33-43.

[18] H.-C. Chang, J.-J.J. Wang, A stochastic grinding force model considering random grit distribution, Int. J. Machine Tools Manufacture. 48 (2008) 1335-1344.

[19] G. Warnecke, U. Zitt, Kinematic Simulation for Analyzing and Predicting High-Performance Grinding Processes, CIRP Annals - Manufacturing Technology. 47 (1998) 265-270.

[20] M. Deichmueller, B. Denkena, K.M. de Payrebrune, M. Kröger, S. Wiedemann, A. Schröder, C. Carstensen, Modeling of Process Machine Interactions in Tool Grinding, in: B. Denkena, F. Hollmann (Eds.), Process Machine Interactions, Springer, Berlin Heidelberg, 2013, pp. 143-176.

[21] K.M. de Payrebrune, M. Kröger, An integrated model of tool grinding: challenges, chances and limits of predicting process dynamics, Production Engineering. 10 (2016) 421-432.

[22] K.M. de Payrebrune, M. Kröger, Dynamical aspects in modeling long cantilevering workpieces in tool grinding, J. Sound Vibration 355 (2015) 407-417. 